\title{
Epidemiological study in operated patients with cholelithiasis and analysis of risk factors
}

\author{
Saxena P.K. ${ }^{1}$, Golandaj V.K. ${ }^{2}$, Malviya V.K ${ }^{3}$. \\ ${ }^{1}$ Dr. Pradeep Kumar Saxena, Assistant Professor, RKDF Medical College, Bhopal, MP, ${ }^{2}$ Dr Vinay Kumar Golandaj, Post \\ Graduate Student, Department of General Surgery, L N Medical College Bhopal, ${ }^{3}$ Dr. Vikas Kumar Malviya, Associate \\ Professor, Department of General Surgery, L.N. Medical College Bhopal, Madhya Pradesh, India
}

Corresponding Author: Dr. Vinay Kumar Golandaj, Post Graduate Student, Department of General Surgery, L.N. Medical College Bhopal, Madhya Pradesh, India, Madhya Pradesh, India. E-mail: drvinayhot@gmail.com

\begin{abstract}
Introduction: Cholelithiasis is a very common gall bladder disease in India especially in northern area which may be symptomatic or asymptomatic. Cholelithiasis is more common in adult population and its incidence increases with age. Most common risk factors associated with cholelithiasis are female sex, rapid weight loss, diabetes mellitus, obesity, hormone therapy and oral contraceptives use etc. Laparoscopic cholecystectomy is preferred over the open approach in symptomatic and asymptomatic cholelithiasis. Methods: 171 operated patients of cholelithiasis were included in this study. All the relevant details were obtained from medical record department with all demographic details. Result: Highest number of patients of cholelithiasis (59.6\%) belongs to the middle age group of 41-60 years. The male to female ratio was 1:1.7 with female preponderance. Patients with middle socioeconomic status were most commonly affected group (45.0\%). Most of the patients were symptomatic in past with history of symptoms of cholecystitis (78.9\%). Risk factors commonly associated with cholelithiasis are increasing age, female gender, family history or genetics, obesity, rapid weight loss, sedentary lifestyle, pregnancy, drugs like ceftiaxone, octreotide and thiazide diuretics, total parenteral nutrition or fasting, diseases like cirrhosis, chronic hemolysis and ileal Crohn's disease. In the present study, 63.15\% patients were operated with open cholecystectomy method and 36.8\% patients with laparoscopic approach. Conclusion: Cholelithiasis is associated with multiple risk factors. Cholelithiasis can be easily diagnosed in ultrasonography of abdomen and early diagnosis may be beneficial for patients as this may be treated with conservative or operative management, prior to the development of complications.
\end{abstract}

Keywords: Cholelithiasis, Epidemiological study; Risk factor

\section{Introduction}

Cholelithiasis is a very common gall bladder disease in India which may be symptomatic or asymptomatic. Most of the patients with cholelithiasis are asymptomatic and usually diagnosed during ultrasonography as an incidental finding. Prevalence of cholelithiasis in India is very common especially in northern area. Cholelithiasis is a chronic recurrent hepatobiliary disease, the basis for which is the impaired metabolism of cholesterol, bilirubin and bile acids, which is characterized by the formation of gallstones in the hepatic bile duct, common bile duct, or gallbladder [1]. Cholelithiasis is more common in adult population and its incidence increases with age.

The etiology of cholesterol cholelithiasis is considered multifactorial, with interaction of genetic and environmental factors [2].

Manuscript Received: $14^{\text {th }}$ November 2019

Reviewed: $24^{\text {th }}$ November 2019

Author Corrected: $29^{\text {th }}$ November 2019

Accepted for Publication: $4^{\text {th }}$ December 2019
Most common risk factors associated with cholelithiasis are diabetes mellitus, obesity, female sex, rapid weight loss, hormone therapy and oral contraceptives use $[3,4]$.

Symptomatic patients usually present with pain in right upper quadrant of abdomen, vomiting with fever suggestive of cholelithiasis and its complications such as acute cholecystitis, gallstone associated pancreatitis and ascending cholangitis. A history of gallstones appears to carry the highest risk for gallbladder cancer, with a relative risk of 4.9 [5].

Ultrasonography is the gold standard investigation for cholelithiasis and its related complications. Ultrasonography is an ideal means to quantitate the frequency of gallstone disease, being a noninvasive and safe imaging technique that accurately can detect the point prevalence of gallstones in a defined asymptomatic population [3]. 


\section{Original Research Article}

The conservative management of acute calculus cholecystitis is antibiotics, analgesics, supportive and symptomatic. Gall stone dissolution therapy is usually not effective and advised in the condition when patient is not fit for surgery. Cholecystectomy is the operative procedure for asymptomatic, symptomatic and complicated cholelithiasis. Laparoscopic approach is preferred over the open approach in cholelithiasis. There is no published epidemiological study on cholelithiasis which categorized the risk factors in this region. The aim of this retrospective study is to compile the epidemiological data in patients with cholelithiasis and assess the risk factors associated with this disease.

\section{Methods}

Place of study: R.K.D.F Medical College and Hospital Bhopal (M.P.).

Type of study: Retrospective study

Sampling Method: Consecutive

Sample collection: Data were collected from medical record department. 171operated patients of cholelithiasis, fulfilling all the inclusion criteria were included in this study. All the relevant details were obtained from medical record department with all demographic details. Data were tabulated using detailed proforma. Following details of patients were recorded like age, sex, socioeconomic status, symptoms and risk factors. In all case records of admitted patients with cholelithiasis, final diagnosis was made on the basis of detailed history, clinical examination and ultrasonography. Conservative management was preferred in cholelithiasis with acute cholecystitis and operated later on. Patients with cholelithiasis were treated by open or laparoscopic cholecystectomy. All the relevant collected data was compiled on master chart.

Inclusion criteria: Patients with cholelithiasis of age group 20 to 80 years who were admitted in surgery ward and operated by open or laparoscopic cholecystectomy were included in the study. All the asymptomatic patients with multiple gall stones and gall stone with size more than 2-3 cm, diagnosed in ultrasonography for other abdominal pathology as an incidental finding.

Exclusion criteria: Patients with acute cholecystitis and complicated cholelithiasis like ascending cholangitis, common bile duct stones and gall bladder carcinoma were excluded. Pregnant female patients and patients less than 20 years of age were also excluded from study. People who refused to participate in the study for any reason were also not included in the study.

Statistical methods: Results were shown in tables, comparing their numbers and percentages by scientific calculator and standard appropriate statistical formula.

Ethical permission: Approved

\section{Results}

The aim of this study was to analyze statistics in patients with cholelithiasis to explain the demographic details and risk factors associated with cholelithiasis. Records of patients with cholelithiasis who were admitted in surgical wards were obtained from medical record department and after analysis the data following observations and results were obtained.

Table-1: Age wise distribution.

\begin{tabular}{|c|c|c|}
\hline Age group (years) & Total admission & \% \\
\hline $20-40$ & 46 & $26.9 \%$ \\
\hline $41-60$ & 102 & $59.6 \%$ \\
\hline $61-80$ & 23 & $13.4 \%$ \\
\hline & 171 & \\
\hline
\end{tabular}

Age - Highest number of patients belongs to the middle age group of 41-60 years (Table 1).

Table-2: Sex wise distribution.

\begin{tabular}{|c|c|c|}
\hline & Total admission & \% \\
\hline Male & 64 & $37.4 \%$ \\
\hline Female & 107 & $59.6 \%$ \\
\hline & 171 & \\
\hline
\end{tabular}

Sex - The male to female ratio was $1: 1.7$. Out of total admission of $171,37.4 \%$ were male patients and $59.6 \%$ were female patients (Table 2). 


\section{Original Research Article}

Table-3: Socioeconomic status wise distribution.

\begin{tabular}{|l|c|c|}
\hline & Total admission & \% \\
\hline Lower & 68 & $39.7 \%$ \\
\hline Middle & 77 & $45.0 \%$ \\
\hline Upper & 26 & $15.2 \%$ \\
\hline Total & 171 & \\
\hline
\end{tabular}

Patients with middle socioeconomic status were most commonly affected group (45.0\%) with cholelithiasis (Table 3 ).

Table-4: History of complaints/symptoms.

\begin{tabular}{|l|c|c|}
\hline & Number of patients & \% \\
\hline Asymptomatic & 36 & $21.0 \%$ \\
\hline & & $78.9 \%$ \\
\hline Symptomatic & 135 & $57.3 \%$ \\
\hline - Pain in right upper quadrant of abdomen & 98 & $21.6 \%$ \\
\hline - Ploain in epigastrium of abdomen & 37 & $50.3 \%$ \\
\hline - Nausea and vomiting & 86 & $45.6 \%$ \\
\hline
\end{tabular}

Most of the patients were symptomatic in past with history of symptoms of cholecystitis (78.9\%). Rests of the patients (21\%) were asymptomatic who were diagnosed incidentally during ultrasonography for other abdominal pathology (Table 4).

Table-5: Common risk factors for cholelithiasis.

\begin{tabular}{|l|c|c|}
\hline \multicolumn{1}{|c|}{ Risk Factors } & Number of patients & \% \\
\hline Advanced Age & 125 & $72.1 \%$ \\
\hline Female gender & 107 & $59.6 \%$ \\
\hline Family history or genetics & 86 & $50.3 \%$ \\
\hline Obesity & 102 & $59.6 \%$ \\
\hline Rapid weight loss & 43 & $25.1 \%$ \\
\hline Sedentary lifestyle & 108 & $63.1 \%$ \\
\hline Pregnancy & 3 & $1.7 \%$ \\
\hline $\begin{array}{l}\text { Drugs like ceftiaxone, octreotide and } \\
\text { thiazide diuretics, and }\end{array}$ & 7 & $4.3 \%$ \\
\hline Total parenteral nutrition & 2 & $1.1 \%$ \\
\hline Fasting. & 6 & $3.5 \%$ \\
\hline $\begin{array}{l}\text { Diseases like cirrhosis, chronic hemolysis } \\
\text { and ileal Crohn's disease }\end{array}$ & 2 & $1.1 \%$ \\
\hline
\end{tabular}

Risk factors commonly associated with cholelithiasis in the present study are advanced age, female gender, family history or genetics, obesity, rapid weight loss, sedentary lifestyle, pregnancy, drugs like ceftiaxone, octreotide and thiazide diuretics, total parenteral nutrition or fasting, diseases like cirrhosis, chronic hemolysis and ileal Crohn's disease (Table 5).

Table-6: Management of cholelithiasis

\begin{tabular}{|c|c|c|}
\hline & Procedure & \% \\
\hline Open cholecystectomy & 108 & $63.15 \%$ \\
\hline Laparoscopic cholecystectomy & 63 & $36.8 \%$ \\
\hline Total & $\mathbf{1 7 1}$ & \\
\hline
\end{tabular}




\section{Original Research Article}

In the present study 63.15 patients were operated with open cholecystectomy method and $36.8 \%$ patients with laparoscopic approach (Table 6).

\section{Discussion}

Cholelithiasis represents a significant burden for healthcare systems worldwide and is one of the most common disorders among patients presenting to emergency rooms with abdominal discomfort e.g. epigastric pain, nausea, vomiting, loss of appetite [6, 7]. Cholelithiasis is common with the incidence ranging from $10 \%$ to $20 \%$ of world population, $11 \%$ of the general population of USA [8]. The estimated prevalence of gallstone disease in India has been reported as $2 \%$ to $9 \%$ $[9,10]$. It is seven times more frequent in North compared to South India [11].

The frequency of gallstones increases with age, escalating markedly after age 40 to become 4 to 10 times more likely in older individuals [3]. Age wise distribution analysis of the data in the present study also reveals that most common age group affected with cholelithiasis was middle age group (41-60 years). The reason for more incidence of cholelithiasis in middle age group may be due to increase in the rate of gall stone formation with increasing age. After 20 years of age, the rate of gallstone formation increases with each decade [12].

The female gender is a generally recognized risk factor of gall bladder disease $[13,14]$. Sex wise distribution of cholelithiasis in the present study reveals that the male to female ratio was 1: 1.7. In another study by Syam sundar et al, there was a female-to-male preponderance were observed with M: F Ratio of 1:1.5, which is in accordance to the present study [15]. Out of total admission of 171, $37.4 \%$ were male patients and $59.6 \%$ were female patients. This may be due to the effect of estrogen which increases biliary cholesterol secretion. In the present study, patients with middle socioeconomic status were most commonly affected group (45.0\%) with cholelithiasis and less common in higher socioeconomic group (15.2\%). Diehl et al analyzed the socioeconomic status in Mexican Americans as compared with Non-Hispanic whites and observed that those living in affluent neighborhoods, with high occupational status, high family incomes, and high educational attainments had lower rates of gallstones than those lower on the social scale [16].

This lower incidence of cholelithiasis in higher socioeconomic status may be due to health seeking behavior in this group. The other studies failed to find an association, the relation between socioeconomic status and gallstone disease is still controversial. Most of the patients in the present study were symptomatic in past with history of symptoms of cholecystitis ( $78.9 \%)$.
Rests of the patients (21\%) were asymptomatic who were diagnosed incidentally during ultrasonography for other abdominal pathology. Most of the symptomatic patients had more than one complains in past. This fact is contradictory to the finding by a study suggestive that most gallstones are clinically "silent," an incidental finding often uncovered during abdominal ultrasound being performed for another reason [17]. The risk of developing complications is 3.3 times greater in symptomatic than in asymptomatic patients, statistical analysis also revealed that the risk of complications is about ten times greater in patients with both risk factors (age $>60$ and symptomatic) than in those with neither [18].

Most common symptom of cholelithiasis in the present study was pain in right upper quadrant of abdomen and epigastrium ( $57.3 \%$ and $21.6 \%$ respectively). Abdominal pain in case of acute cholecystitis with cholelithiasis is a result of an acute increase in pressure inside the biliary tract or obstruction of the gallbladder outlet causing inflammation of the gallbladder. A review of recent controlled trials suggests that the pain of biliary colic is constant and infrequent, comes in episodes lasting 1-5 hours, is located in the epigastrium or right upper quadrant of the abdomen and characteristically occurs at night [19].

In the present study, $45.6 \%$ patient had additional symptoms of nausea and vomiting. 50.3\% patients in the present study had complaints of bloating and flatulent dyspepsia. But according to Egbert et al flatulent dyspepsia, a symptom complex of vague pain in the right upper quadrant, fatty-food intolerance and bloating are probably not related to the presence of gallstones in the majority of patients [19].

In the present study following risk factors for cholelithiasis were studied such as age, female gender, family history or genetics, obesity, rapid weight loss and a sedentary lifestyle. Other less common risk factors include pregnancy, drugs like ceftiaxone, octreotide and thiazide diuretics, and total parenteral nutrition or fasting. Diseases like cirrhosis, chronic hemolysis and ileal Crohn's disease. Other studies also suggest the similar risk factors. Risk factors associated with cholelithiasis in the West include gender $(\mathrm{F}>\mathrm{M})$, age, obesity, metabolic syndrome, rapid appetite loss, hepatitis $\mathrm{C}$, cirrhosis, and high caloric intake $[20,21]$.Hung et al also suggested the risk factors for cholelithiasis in a study which were obesity, hyperlipidemia, hepatitis B infection, hepatitis $\mathrm{C}$ infection, and cirrhosis in both genders, and menopause in females [22]. 


\section{Original Research Article}

Cholecystectomy in general and laparoscopic cholecystectomy in particular is safe procedures in the treatment of patients with gallstones. [23, 24]. In the present study, $63.15 \%$ patients were operated with open cholecystectomy method and $36.8 \%$ patients with laparoscopic approach. In the present study, most of the asymptomatic patients were operated prophylactically, with gall stone size more than $2-3 \mathrm{~cm}$. According a study, prophylactic cholecystectomy for asymptomatic gallstones may be indicated in patients with large gallstones, greater than $2 \mathrm{~cm}$ in diameter, as the risk of malignancy was more than doubled for patients with gallstone diameters of 2.0$2.9 \mathrm{~cm}$; the neoplastic risk was more than 10 -fold in those with gallstone diameters of $\geq 3 \mathrm{~cm}$ [25].

The present study also included asymptomatic patients with multiple gall stones in our series as there is additional risk of gall stone passage through cystic duct and common bile duct. Stones in the common bile duct can cause biliary obstruction, cholangitis, pancreatitis, or secondary biliary cirrhosis in patients who have had the stones for a long time [26]. Justification for prophylactic cholecystectomy is usually based on the studies of Wenckert and Robertson who noted that $6.3 \%$ of untreated, mildly, symptomatic gallstone carriers developed symptoms each year of follows up [27].

Limitation of present study is that it is a very small epidemiological study. In this small retrospective study, data related to risk factors obtained were based on case records of patients which are less informative than a prospective study. Thus a prospective study needed for evaluation of the risk factors associated with cholelithiasis.

\section{Conclusion}

Cholelithiasis is one of the common gastrointestinal diseases usually found in patients with risk factors like female gender, advanced age, obesity, metabolic syndrome, rapid appetite loss, cirrhosis, high caloric intake, hyperlipidemia, hepatitis B infection, hepatitis C infection, cirrhosis, and menopause in females. Cholelithiasis can be easily diagnosed in ultrasonography of abdomen. Early diagnosis may be beneficial for patients as this may be treated with conservative or operative management, prior to the development of complications.

\section{What the study adds to the existing knowledge?}

This epidemiologic study of cholelithiasis and its risk factors in this region can guide us to better understanding of the trends of this disease, which is most commonly encountered in our society.
This useful information may aid in the assessment and definitive care of these patients with cholelithiasis.

\section{Author's contributions}

Dr. Pradeep Kumar Saxena formulated the aims \& objectives with study design, supervised and guided for study.

Dr. Vikas Kumar Malviya helped in data collection from medical record department

Dr. Vinay Kumar Golandaj helped in data analysis with preparation of the manuscript.

Funding: No funding sources

Conflict of interest: None declared

Ethical approval: This study was approved by the Institutional Ethics Committee

\section{Reference}

1. Reshetnyak VI. Concept of the pathogenesis and treatment of cholelithiasis. World J Hepatol. 2012;4(2):1834. doi: 10.4254/wjh.v4.i2.18.

2. Amigo L, Zanlungo S, Mendoza H, Miquel JF, Nervi F. Risk factors and pathogenesis of cholesterol gallstones: state of the art. Eur Rev Med Pharmacol Sci. 1999;3(6):241-246

3. Stinton LM, Shaffer EA. Epidemiology of gallbladder disease: cholelithiasis and cancer. Gut and liver. 2012;6(2):172-187. doi: 10.5009/gnl.2012.6.2.172.

4. Acalovschi M, Lammert F. The growing global burden of gallstone disease. World Gastroenterology News. 2012;17 (4):6-9.

5. Randi G, Franceschi S, La Vecchia C. Gallbladder cancer worldwide: geographical distribution and risk factors. Int $\mathrm{J}$ Cancer. 2006;118 (7):1591-1602. doi: https://doi.org/10.1002/ijc.21683.

6. Bodmer M, Brauchli YB, Krähenbühl S, Jick SS, Meier CR. Statin use and risk of gallstone disease followed by cholecystectomy. JAMA. 2009;302(18):2001-2007. doi: 10.1001/jama.2009.1601.

7. Marx J, Walls R, Hockberger R. Rosen's Emergency Medicine-Concepts and Clinical Practice E-Book. Elsevier Health Sciences; 2013 Aug 1.

8. Gibney EJ. Asymptomatic gallstones. Brit J Surg. 1990;77 (4):368-372. doi: https://doi.org/10.1002/bjs 1800770405 . 


\section{Original Research Article}

9. Khuroo MS, Mahajan R, Zargar SA, Javid G, Sapru S. Prevalence of biliary tract disease in India: a sonographic study in adult population in Kashmir. Gut. 1989;30 (2):201-205. doi: http://dx.doi.org/10.1136/gut. 30.2.201.

10. Unisa S, Jagannath P, Dhir V, Khandelwal C, Sarangi L, Roy TK. Population-based study to estimate prevalence and determine risk factors of gallbladder diseases in the rural Gangetic basin of North India. HPB. 2011;13(2):117125. doi: 10.1111/j.1477-2574.2010.00255.x.

11. Malhotra SL. Epidemiological study of cholelithiasis among railroad workers in India with special reference to causation. Gut. 1968;9(3):290-295. doi: 10.1136/gut. 9.3.290.

12. Bergman S, Sourial N, Vedel I, Hanna WC, Fraser SA, Newman D, et al. Gallstone disease in the elderly: are older patients managed differently? Surg Endoscop. 2011;25(1):55-61. doi: 10.1007/s00464-010-1128-5.

13. Novacek G. Gender and gallstone disease. Wiener Medizinische Wochenschrift. 2006;156(19-20):527-533. doi: https://doi.org/10.1007/s10354-006-0346-x.

14. Völzke H, Baumeister SE, Alte D, Hoffmann W, Schwahn C, Simon P, et al. Independent risk factors for gallstone formation in a region with high cholelithiasis prevalence. Digest. 2005;71 (2): 97-105. doi: https://doi. org $/ 10.1159 / 000084525$.

15. Byna SS. Epidemiological and pathological study of resected gall bladders due to cholelithiasis. Int $\mathrm{J}$ Chem Lifesci. 2013;2 (7):1195-1198.

16. Diehl AK, Rosenthal M, Hazuda HP, Comeaux PJ, Stern MP. Socioeconomic status and the prevalence of clinical gallbladder disease. J Chron Dis. 1985;38 (12):1019-1026.

17. Halldestam I, Enell EL, Kullman E, Borch K. Development of symptoms and complications in individuals with asymptomatic gallstones. Brit J Surg. 2004;91(6):734-738. doi: https://doi.org/10.1002/bjs.4547.
18. Murshid KR. Asymptomatic gallstones: Should we operate? Saudi J Gastroenterol. 2007;13(2):57-69.

19. Egbert AM. Gallstone symptoms: myth and reality. Postgraduate Med. 1991; 90 (5):119-126. doi: https://doi. org/ 10.1080/00325481.1991.11701076.

20. Shaffer EA. Epidemiology of gallbladder stone disease. Best Pract Res Clinic Gastroenterol. 2006;20 (6): 981-996. doi: https://doi.org/10.1016/j.bpg.2006. 05.004.

21. Acalovschi M, Buzas C, Radu C, Grigorescu M. Hepatitis $\mathrm{C}$ virus infection is a risk factor for gallstone disease: a prospective hospital-based study of patients with chronic viral C hepatitis. J Viral Hepatitis. 2009;16 (12): 860-866. doi: 10.1111/j.1365-2893.2009. 01141.x. Epub 2009 May 26.

22. Hung SC, Liao KF, Lai SW, Li CI, Chen WC. Risk factors associated with symptomatic cholelithiasis in Taiwan: a population-based study. BMC Gastroenterol. 2011;11(1):111. doi: 10.1186/1471-230X-11-111.

23. Coelho JC, VizzotoJr AO, Salvalaggio PR, Tolazzi AR. Laparoscopic cholecystectomy to treat patients with asymptomatic gallstones. Digest Surg. 2000;17(4):344347. doi: https://doi.org/10.1159/000018876.

24. Spina GP, Pagani M. Prophylactic cholecystectomy for gallbladder calculosis. Ann Ital Chir. 1998;69(6):713-717.

25. Diehl AK. Gallstone size and the risk of gallbladder cancer. JAMA. 1983;250(17):2323-2326. doi:https://doi. org/10.1001/jama.1983.03340170049027.

26. Almadi MA, Barkun JS, Barkun AN. Management of suspected stones in the common bile duct. CMAJ. 2012;184 (8):884-892. doi: 10.1503/cmaj.110896.

27. Wenckert A, Robertson B. The natural course of gallstone disease: eleven-year review of 781 nonoperated cases. Gastroenterol. 1966;50 (3):376-381. doi: https://doi. org/10.1016/S0016-5085(66)80078-1.

\section{How to cite this article?}

Saxena P.K., Golandaj V.K., Malviya V.K. Epidemiological study in operated patients with cholelithiasis and analysis of risk factors. Surgical Update: Int J surg Orthopedics.2019;5(5):340-345.doi:10.17511/ijoso.2019.i05.05 